\title{
Volatile Toluene and Xylene Removal Efficiency of Foliage Plants as Affected by Top to Root Zone Size
}

\author{
Kwang Jin Kim¹, Hyun Hwan Jung, Hyo Won Seo, and Jung A. Lee \\ Urban Agriculture Research Division, National Institute of Horticultural and \\ Herbal Science, Rural Development Administration, Suwon 441-440, Korea
}

\author{
Stanley J. Kays \\ Department of Horticulture, 1111 Plant Sciences Building, University of \\ Georgia, Athens, GA 30602-7273
}

Additional index words. indoor air, phytoremediation, top to media ratio

\begin{abstract}
Phytoremediation of volatile organic compounds in indoor air involves both the plant and microbes in the media; however, removal rate is typically expressed on a leaf area basis. We determined the effect of root media volume on phytoremediation rate of volatile toluene and xylene to determine if there is a change in phytoremediation efficiency. Phytoremediation rate was calculated based on the aboveground space occupied by the plant and on the leaf area. Foliage plants of Fatsia japonica and Draceana fragrans 'Massangeana' were grown in different-sized pots $(1,2,4,6$, and $12 \mathrm{~L})$ that gave aerial plant to root zone volume ratios of 21:1, 21:2, 21:3, and 21:6. Total root volume and root fresh weight increased in $D$. fragrans with increasing media volume, whereas root density per unit of media volume decreased in both species. The efficiency of volatile toluene and xylene removal by the plants was increased as the root zone volume increased, whereas removal efficiency per unit media volume increased and then decreased. The highest volatile toluene and xylene removal efficiency was at a ratio of 21:3 (aerial plant:root zone volume) in $F$. japonica and 21:2 in $D$. fragrans. When phytoremediation efficiency was expressed on a leaf area basis, the phytoremediation rate for toluene and xylene increased progressively for both species with increasing media volume and as root volume increased. Calculating the amount of plant material needed within a home or office to obtain sufficient volatile organic compound (VOC) removal cannot be accurately predicted base solely on a leaf area (LA) or aboveground volume basis.
\end{abstract}

Indoor plants can remove VOCs from the air in homes and offices, some of which are known to be highly toxic. The rate of removal (generally expressed on a LA basis as $\left.\mu \mathrm{g} \cdot \mathrm{m}^{-3} \cdot \mathrm{m}^{-2} \cdot \mathrm{h}^{-1}\right)$ is known to differ substantially among species (Kays, 2011); and as the plant size increases, the removal potential per plant increases. The amount of plant material needed to reduce the VOC concentration within a structure varies with the steady-state VOC concentration, air exchange rate of the building, VOC removal rate of the plant species selected, percent reduction in concentration desired, and the plant mass present, among other factors (e.g., temperature, light intensity). The acceptable number of plants that can be placed in a building depends on a range of factors, among which the physical volume of the building and the volume of space occupied per plant are critical.

The relationship between the aboveground size of the plant and its VOC removal potential is further complicated by the fact that microorganisms in the root zone elimi-

Received for publication 24 Sept. 2013. Accepted for publication 9 Dec. 2013.

${ }^{1}$ To whom reprint requests should be addressed; e-mail kwangjin@korea.kr. were growing in pots of differing diameters and media volumes.

\section{Materials and Methods}

Plant materials. Fatsia japonica (Thunb.) Decne. \& Planch. and Dracaena fragrans (L.) Ker Gawl. cv. Massangeana foliage plants were obtained from a commercial market. $F$. japonica and $D$. fragrans were selected as woody species with fibrous roots and a central tap root, respectively. The three-dimensional volume occupied by the aerial portion of the plant was calculated assuming they were cylindrical as $v=\pi r^{2} h$ with the radius $(r)$ and height $(h)$. The plants were transplanted into pots specifically fabricated for the experiment (Fig. 1), containing a uniform growing medium [i.e., Mix \#4 (Sun Gro Horticulture, Bellevue, WA), bark-humus (Biocom. Co., Seoul, Korea), and sand at 5:1:1, v/v/v]. Mix \#4 contained Canadian sphagnum peat moss ( $55 \%$ to $65 \%$ by volume), perlite, dolomitic lime, gypsum, and a wetting agent. All plants were grown in a greenhouse for 5 months after transplanting. The pots were $1,2,4,6$, and 12 (L) in volume (Fig. 2). All pots were $20 \mathrm{~cm}$ in height and had growing medium filled to a height of $16 \mathrm{~cm}$. To maximize the accuracy of determining the air space volume occupied by each plant, nine pot plants were arranged as a square and the width measured, which was divided by three to obtain the average radius of each plant (Kim and Lee, 2008); the height was measured from the media surface to the top of the leaves. The air space volume of the aboveground portion of $F$. japonica plants was $21 \mathrm{~L}$; they were planted in 1-, 2-, 4-, and 6-L pots. $D$. fragrans plants ( $42 \mathrm{~L}$ ) were planted in 2-, 4-, 6-, and 12-L pots. Each species had identical aboveground to media volume ratios for the various pot sizes of 21:1, 21:2, 21:3, and 21:6. The plants were acclimated within the indoor environment used for the experiments for 1 month $\left(23 \pm 2{ }^{\circ} \mathrm{C}, 40 \% \pm 5 \%\right.$ relative humidity, $20 \pm 2 \mu \mathrm{mol} \cdot \mathrm{m}^{-2} \cdot \mathrm{s}^{-1}$ photosynthetically active radiation, and a 12-h photoperiod). The plants were watered every $3 \mathrm{~d}$ with the excess water allowed to drain. All plants were watered the day before the gas treatments. Three pots of each pot size were placed in a chamber. Three replicates (chambers) of each treatment were tested. Chambers without plants were used to determine toluene and xylene losses not resulting from the plants (e.g., leakage, adsorption, chemical reactions). After removal of the media, the root volume was measured using water displacement in a 2-L graduated cylinder (Fig. 3) with root density calculated as root volume divided by media volume. Leaf area was determined using a LI-3100 leaf area meter (LI-COR Inc., Lincoln, NE) at the end of the experiment (root and LA data are presented in Table 1).

Treatment system. The treatment system consisted of controlled-environment rooms (i.e., temperature, light intensity, and relative humidity) containing the test chambers and a gas generator. The test chambers, described by Kim et al. (2011), were $1.0 \mathrm{~m}^{3}(90 \times 90 \times$ $123 \mathrm{~cm}$ ) and impervious to VOCs. Interior air 


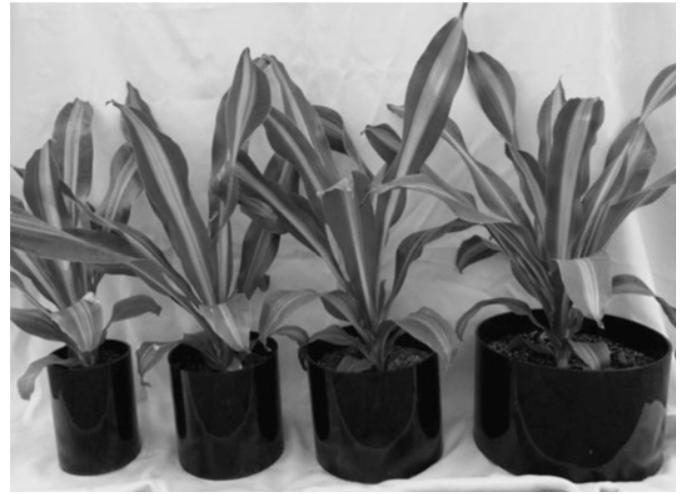

Fig. 1. Dracaena fragrans plants after growing 6 months in four different media volumes $(1,2,4,6 \mathrm{~L} /$ pot $)$.

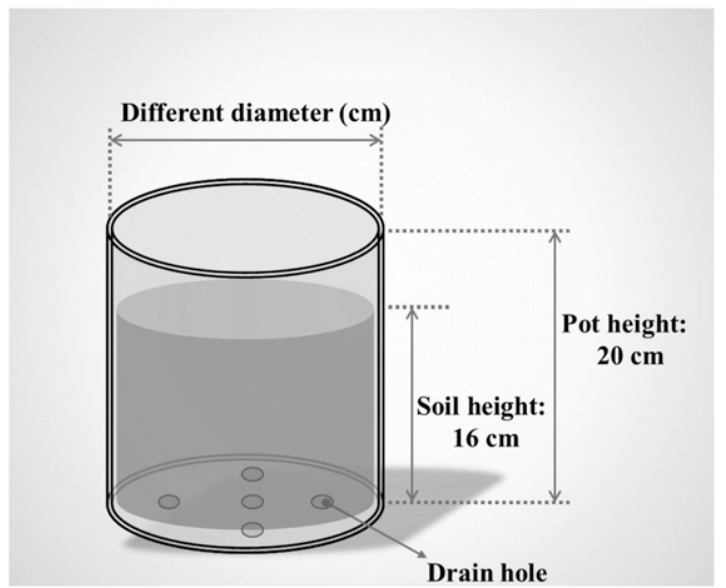

Fig. 2. Pots fabricated for test were $1,2,4,6$, and $12 \mathrm{~L}$ in volume and $20 \mathrm{~cm}$ high with the growing medium filled to $16 \mathrm{~cm}$ from the base.

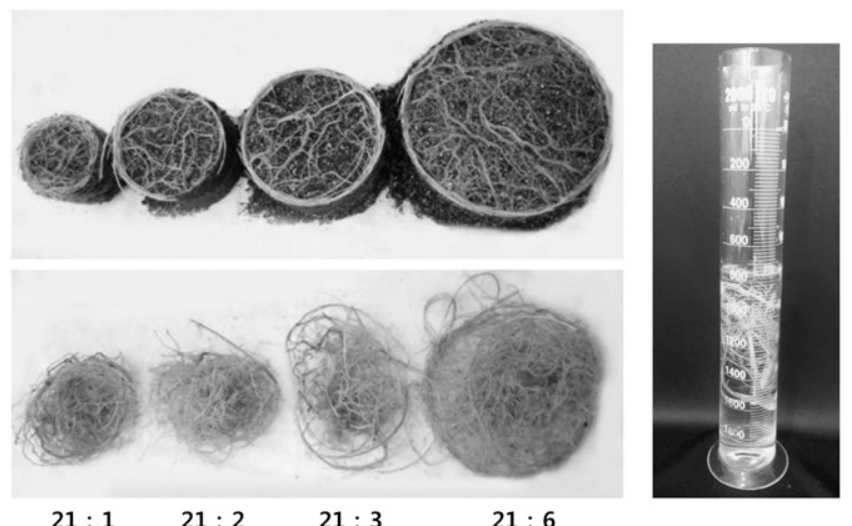

Fig. 3. Isolated roots of Draceana fragrans plants grown in pots that were $2,4,6$ and $12 \mathrm{~L}$ in volume gave aerial plant to root zone volume ratios of $21: 1,21: 2,21: 3$, and 21:6, respectively. Root volume was determined by water displacement. was circulated $\left(6 \mathrm{~L} \cdot \mathrm{min}^{-1}\right)$ and tested for toluene and xylene concentration at three positions: 12,70 , and $98 \mathrm{~cm}$ above the base of the chamber.

Gas exposure and measurement. The plants were pretreated with toluene and xylene, which is known to enhance their phytoremediation potential for each gas. Gaseous toluene and xylene were introduced into test chambers containing plants as previously described (Kim et al., 2011) and allowed to equilibrate for $15 \mathrm{~min}$. The internal concentration was determined and corrected to 2.0 $\mu \mathrm{L} \cdot \mathrm{L}^{-1}$ for the stimulation treatment. The plants remained in the stimulation treatment for $12 \mathrm{~h}$ and then were moved to fresh air for $12 \mathrm{~h}$. After the stimulation treatment, the subsequent toluene and xylene removal rate by the plants was determined. Time 0 was after $12 \mathrm{~h}$ in fresh air after the toluene and xylene stimulation treatment. The plants were exposed at $1.0 \mu \mathrm{L} \cdot \mathrm{L}^{-1}$ of each gas and the rate of toluene and xylene removal measured within the chambers after 6 and $12 \mathrm{~h}$ (Kim et al., 2011). Changes in toluene or xylene concentration within the chambers were expressed as cumulative removal on a LA basis $\left(\mathrm{mg} \cdot \mathrm{m}^{-3} \cdot \mathrm{m}^{-2}\right)$ and as the rate of removal $\left(\mathrm{mg} \cdot \mathrm{m}^{-3} \cdot \mathrm{m}^{-2} \cdot \mathrm{h}^{-1}\right)$. Chambers devoid of plants were treated similarly to determine gas losses resulting from chamber effects.

Toluene and xylene quantification. Air samples were collected at the appropriate time intervals using a quartz cold trap [120 $\mathrm{mm}$ long, $2.9 \mathrm{~mm}$ o.d., $1.0 \mathrm{~mm}$ i.d. (inlet), 2.0 $\mathrm{mm}$ i.d. (outlet); Markes International Ltd., Llantrisant, U.K.] connected to each chamber with the air collected for $5 \mathrm{~min}$ at $5 \mathrm{~mL} \cdot \mathrm{min}^{-1}$. An automated thermal desorption system with Air Server autosampler (UNITY; Markes International Ltd.) was connected to the injection port of the gas chromatograph-mass spectrometer (TRACE DSQ; Thermo Electron Co., Waltham, MA). The desorbed sample was cryofocused at $5{ }^{\circ} \mathrm{C}$ for $5 \mathrm{~min}$ on the first few centimeters of the column, desorbed at $280{ }^{\circ} \mathrm{C}$, and separated using a ZB-624 capillary column (30 m length, $0.25 \mathrm{~mm}$ i.d., $1.40 \mathrm{~mm}$ film thickness of $6 \%$ cyanopropylphenyl, 94\% dimethylpolysiloxane; Phenomenex, Torrance, CA). The injection port temperature was $180^{\circ} \mathrm{C}$ with a split ratio of 29:1. Helium was used as the carrier gas at a flow rate of $1.0 \mathrm{~mL} \cdot \mathrm{min}^{-1}$. The column temperature was held at $45^{\circ} \mathrm{C}$ for $1 \mathrm{~min}$ and increased at a rate of $15^{\circ} \mathrm{C} \cdot \mathrm{min}^{-1}$ to $100{ }^{\circ} \mathrm{C}$ and held for $1 \mathrm{~min}$ and then increased at a rate of $5{ }^{\circ} \mathrm{C} \cdot \mathrm{min}^{-1}$ to $135{ }^{\circ} \mathrm{C}$.

Table 1. Root and leaf area data for foliage plants grown at different aerial plant to root zone volume ratios.

\begin{tabular}{|c|c|c|c|c|c|}
\hline \multirow[b]{2}{*}{ Species } & \multirow[b]{2}{*}{ Aerial plant to root zone volume ratios } & \multicolumn{3}{|c|}{ Root } & \multirow[b]{2}{*}{ Leaf area $\left(\mathrm{m}^{2} /\right.$ pot $)$} \\
\hline & & Volume (mL/pot) & Density (mL. $\mathrm{L}^{-1}$ soil volume) & Fresh wt (g/pot) & \\
\hline \multirow[t]{4}{*}{$\overline{F . j a p o n i c a}$} & $21: 1$ & $36.9 \pm 1.5$ & $36.9 \pm 1.5$ & $40.0 \pm 2.3$ & $1.6 \pm 0.05$ \\
\hline & $21: 2$ & $37.1 \pm 1.1$ & $18.6 \pm 0.6$ & $41.1 \pm 0.6$ & $1.3 \pm 0.04$ \\
\hline & $21: 3$ & $38.1 \pm 4.5$ & $12.7 \pm 1.5$ & $43.2 \pm 5.9$ & $1.4 \pm 0.09$ \\
\hline & $21: 6$ & $37.3 \pm 2.0$ & $6.2 \pm 0.3$ & $42.6 \pm 1.1$ & $1.6 \pm 0.01$ \\
\hline \multirow[t]{4}{*}{ D. fragrans } & $21: 1$ & $60.8 \pm 3.3$ & $30.4 \pm 1.7$ & $62.1 \pm 2.4$ & $3.6 \pm 0.27$ \\
\hline & $21: 2$ & $70.2 \pm 3.4$ & $17.6 \pm 0.9$ & $70.1 \pm 5.5$ & $3.6 \pm 0.26$ \\
\hline & $21: 3$ & $80.8 \pm 2.2$ & $13.5 \pm 0.4$ & $86.6 \pm 4.2$ & $3.9 \pm 0.35$ \\
\hline & $21: 6$ & $113.3 \pm 5.9$ & $9.4 \pm 0.5$ & $111.7 \pm 4.0$ & $3.9 \pm 0.35$ \\
\hline
\end{tabular}




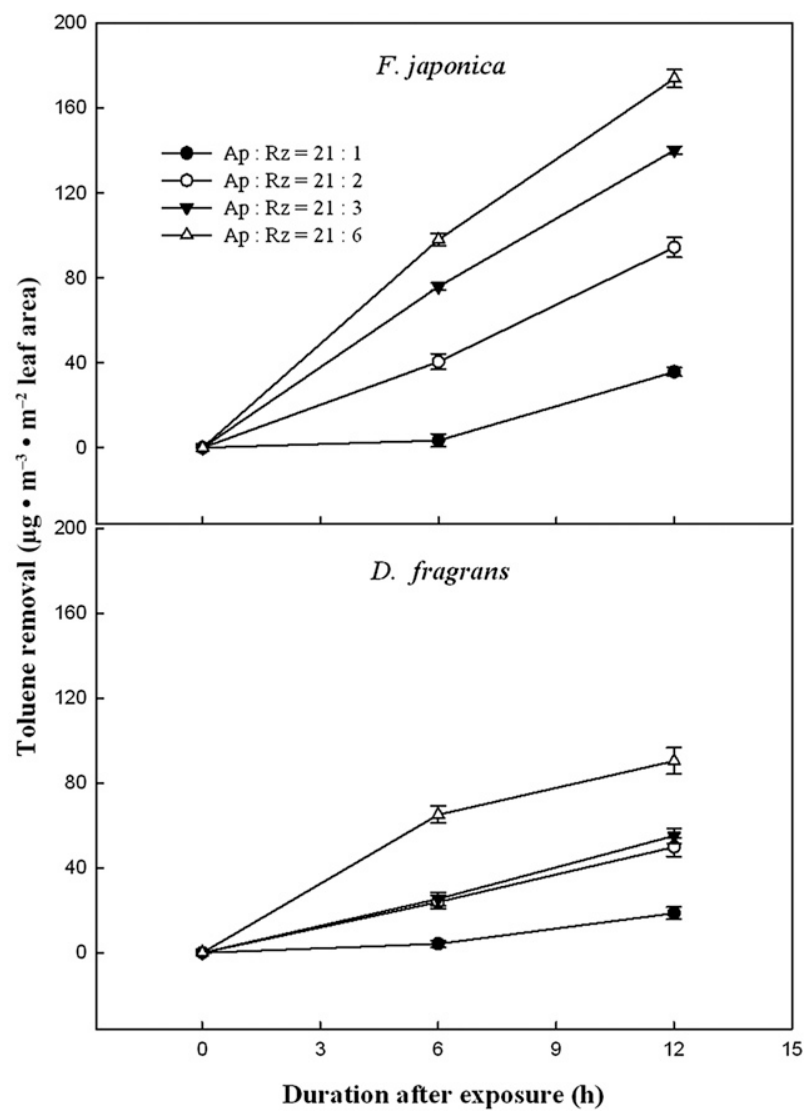

Fig. 4. Toluene removal by foliage plants with differing aerial plant to media volume ratios $(\mathrm{Ap}=$ aerial plant parts; $\mathrm{Rz}=$ root zone). Vertical bars denote the SE.

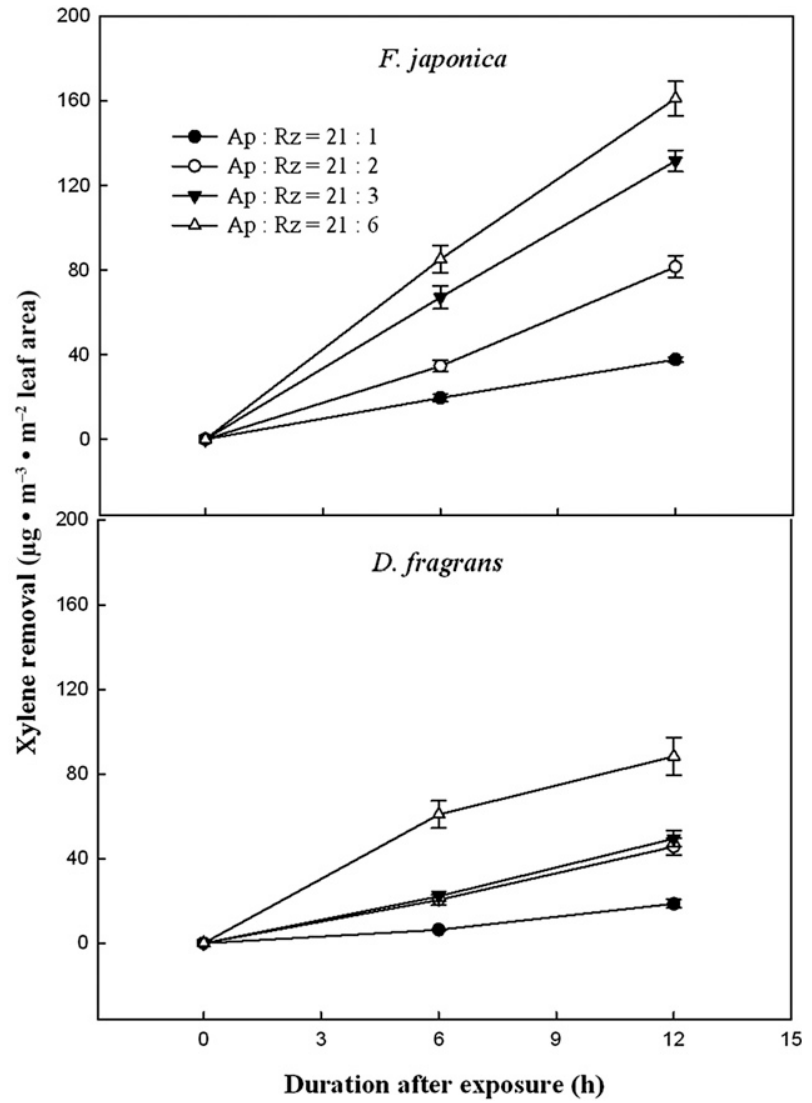

Fig. 5. Xylene removal by foliage plants with differing aerial plant to media volume ratios $(\mathrm{Ap}=$ aerial plant parts; $\mathrm{Rz}=$ root zone). Vertical bars denote the SE.
Data analysis. Gas concentrations were expressed as $\mu \mathrm{g} \cdot \mathrm{m}^{-3}$ with the data normalized to $24 \pm 1{ }^{\circ} \mathrm{C}$ and $100 \mathrm{kPa}$ (Hines et al., 1993). Data were expressed as the average of three replicates. The accumulated removal of toluene or xylene per unit leaf area [Eq. (1)] and the removal efficiency per unit leaf area and time [Eq. (2)] were calculated (Kim et al., 2008, 2011) as:

$\begin{aligned} \text { Accumulated removal }= & {[(\mathrm{Pi}-(\mathrm{Ci}-\mathrm{C}))-\mathrm{P}] } \\ & \times(\mathrm{F} \times \mathrm{CV}) / \mathrm{L}\end{aligned}$

Removal efficiency $=[(\mathrm{Pi}-(\mathrm{Ci}-\mathrm{C}))-\mathrm{P}]$ $\times(\mathrm{F} \times \mathrm{CV}) /(\mathrm{S} \times \mathrm{L})$

$$
\begin{aligned}
\text { VOC removal }= & {[(\mathrm{Pi}-(\mathrm{Ci}-\mathrm{C}))-\mathrm{P}] } \\
& \times(\mathrm{F} \times \mathrm{CV}) /(\mathrm{T} \times \mathrm{L})
\end{aligned}
$$

where $\mathrm{P}$ is the gas concentration measured in a chamber with plants $\left(\mu \mathrm{L} \cdot \mathrm{L}^{-1}\right)$; Pi the initial gas concentration measured in a chamber with plants $\left(\mu \mathrm{L} \cdot \mathrm{L}^{-1}\right)$; $\mathrm{C}$ the gas concentration measured in a chamber without plants $\left(\mu \mathrm{L} \cdot \mathrm{L}^{-1}\right) ; \mathrm{Ci}$ the initial gas concentration measured in a chamber without plants $\left(\mu \mathrm{L} \cdot \mathrm{L}^{-1}\right) ; \mathrm{F}$ the toluene or xylene conversion factor for volume $\left(\mu \mathrm{L} \cdot \mathrm{L}^{-1}\right)$ to mass $\left(\mu \mathrm{L} \cdot \mathrm{L}^{-1}\right)$; $\mathrm{CV}$ the volume of the chamber $\left(\mathrm{m}^{3}\right)$; $\mathrm{L}$ the total LA per chamber $\left(\mathrm{m}^{2}\right)$; and $\mathrm{S}$ the total volume of soil per chamber (L) and $\mathrm{T}$ the gas exposure time (h). The loss of toluene or xylene $(\mathrm{Ci}-\mathrm{C})$ not resulting from the plant and media was determined using empty chambers.

Separation of treatment data points used SE values in the figures, which clearly distinguished the differences.

\section{Results and Discussion}

Fatsia japonica removed toluene at a more rapid rate than $D$. fragrans (Fig. 4); in each case, there was a progressive increase in the total removed. As the media volume increased for both species, the removal rate per unit LA increased. With $F$. japonica, there was a fairly even increment of increase with increasing media volume. In contrast, there was a negligible difference between 4 and $6 \mathrm{~L}$ of media for $D$. fragrans. There was a similar response for xylene removal with $F$. japonica displaying a more rapid rate than $D$. fragrans (Fig. 5). As the media volume increased, the rate of xylene removal increased, although like with toluene, the difference between 4 and $6 \mathrm{~L}$ of media was negligible.

The toluene phytoremediation rate expressed on a per unit volume of media basis increased initially for both species until reaching $4 \mathrm{~L}$ per pot (21:2) and subsequently declined (Fig. 6). In each instance, the aboveground portion of the plant expressed on a volume basis stayed the same, whereas the media volume was progressively increased. 


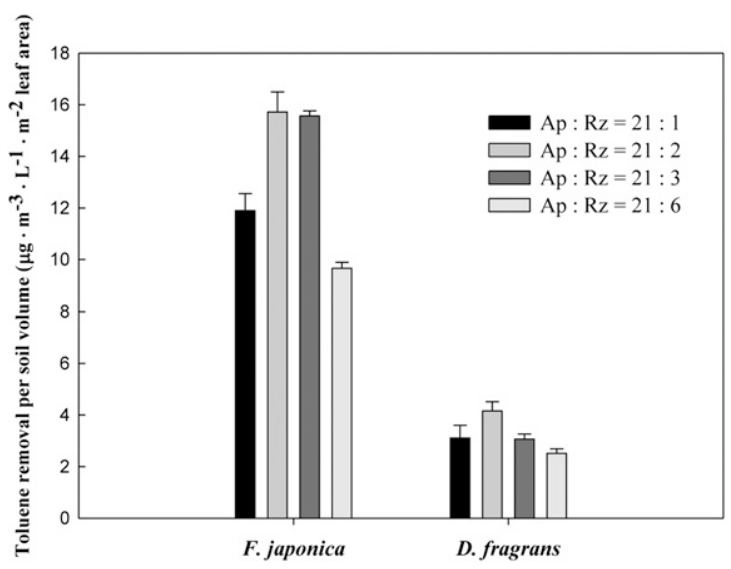

Fig. 6. Toluene removal rate per unit media volume by foliage plants with differing aerial plant to media volume ratios after exposure to $1 \mu \mathrm{L} \cdot \mathrm{L}^{-1}$ of toluene for $12 \mathrm{~h}(\mathrm{Ap}=$ aerial plant parts; $\mathrm{Rz}=$ root zone) Vertical bars denote the SE.

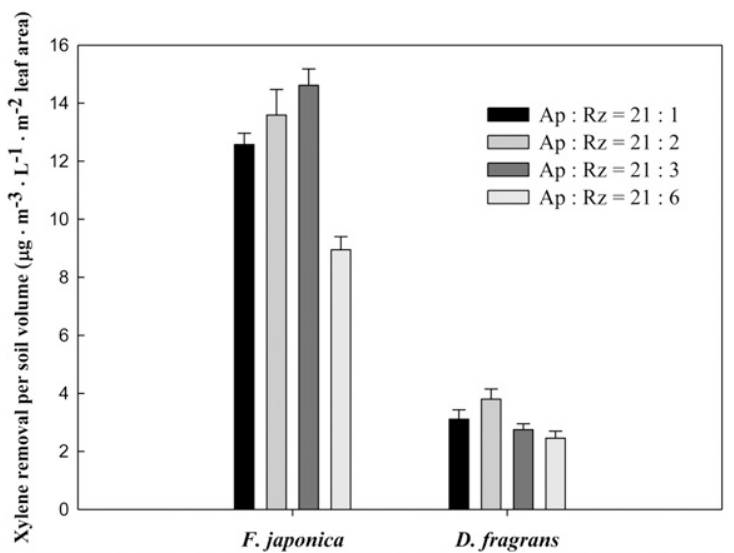

Fig. 7. Xylene removal rate per unit media volume by foliage plants with differing aerial plant to media volume ratios after exposure to $1 \mu \mathrm{L} \cdot \mathrm{L}^{-1}$ of xylene for $12 \mathrm{~h}(\mathrm{Ap}=$ aerial plant parts; $\mathrm{Rz}=$ root zone $)$ Vertical bars denote the SE.

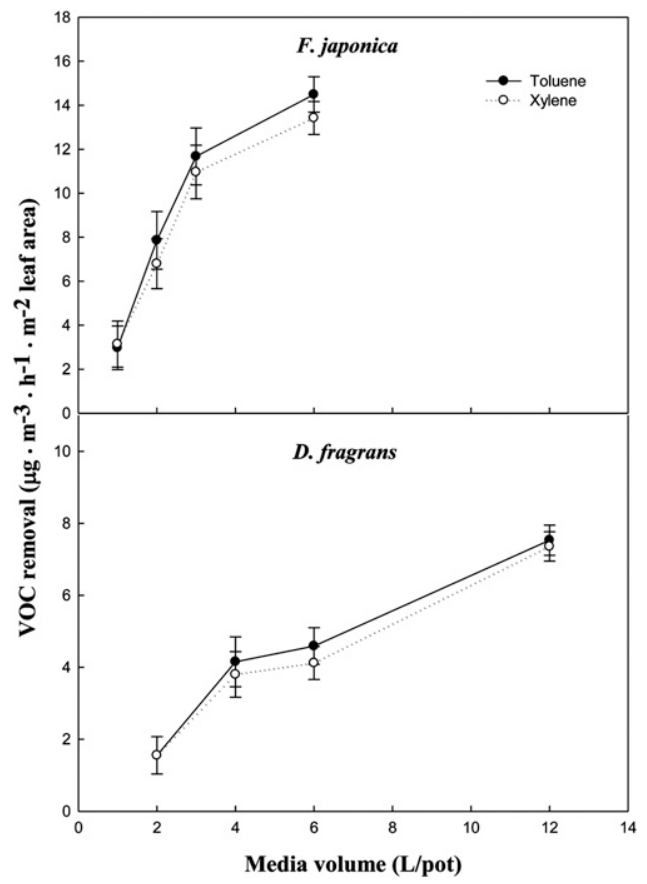

Fig. 8. Effect of plant pot size on phytoremediation rate of toluene and xylene by foliage plants expressed on a leaf area basis. Vertical bars denote the SE.
Like with toluene, xylene removal rate was appreciably lower for $D$. fragrans (Fig. 7). The phytoremediation rate increased until peaking at $6 \mathrm{~L}(21: 3$ aerial plant volume to media volume) in $F$. japonica and subsequently decreased to significantly lower than the highest ratio (21:1). With $D$. fragrans, the rate peaked at a media volume of $4 \mathrm{~L}$ (21:2). Across both chemicals and species, the removal rate was highest at a ratio of $21: 3$ and a root density of $\approx 13 \mathrm{~mL} / \mathrm{L}$. The data indicate that although the aerial plant volume remained constant, increasing the media volume significantly altered the phytoremediation rate. Therefore, although phytoremediation rate is known to vary among species and number and size of plants, altering media volume significantly changed the rate of removal of VOCs.

When the VOC removal rate was expressed on a LA basis, the phytoremediation efficiency increased progressively in both species as the media volume increased (Fig. 8). F. japonica displayed a substantially higher overall rate and increment of increase with increasing media volume than $D$. fragrans. The withinspecies removal of toluene and xylene was comparable for both species. When the effect of increasing media volume was expressed as VOC removal rate per root volume, there was a progressive increase in both species (Fig. 9). Only small increases in the root volume of $F$. japonica resulted in a significant increase in phytoremediation rate, whereas a large increase in media volume of $D$. fragrans resulted in only approximately half of that in $F$. japonica. These differences between species may in part reflect the pronounced difference in the structure of their respective root systems (i.e., central tap root vs. fibrous roots, respectively).

When calculated on the basis of either the aboveground space occupied by the plant or its LA, increasing the media volume resulted in a substantial increase in the rate of removal of toluene and xylene. As the plant increases in size, it is probable that it will reach a point where the phytoremediation rate begins to decline. In either case, calculating the amount of plant material needed within a home or office for sufficient VOC removal cannot be accurately predicted based solely on a LA or aboveground plant volume basis. As a consequence, further research on the relationship between the top and media volumes is needed to accurately predict the true phytoremediation potential of a species.

Because microorganisms are thought to account for $50 \%$ or greater of the VOC removal during the day and greater than $90 \%$ at night, facilitating microbe remediation efficiency would appear to be the most plausible approach to enhancing the overall phytoremediation rate. The recent identification of bacteria strains in the media of indoor plants that can metabolize and live exclusively on volatile toluene as a carbon source underscores the importance of the rhizosphere microbe community in phytoremediation (Zhang et al., 2013). It is highly probable that the microbe population has a far greater potential for 


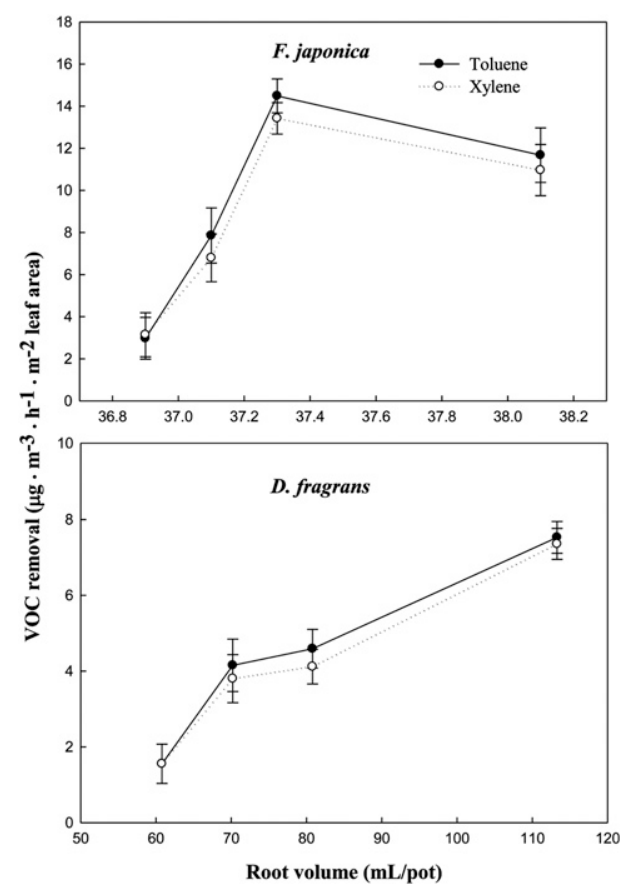

Fig. 9. Relationship between root volume and phytoremediation rate of toluene and xylene by foliage plants expressed on a leaf area basis. Vertical bars denote the SE.

removing the diverse array of VOCs than the plants per se.

In conclusion, the efficiency of volatile toluene and xylene removal by plants increased as the root zone volume increased, whereas removal efficiency per unit media volume increased and then decreased. As a needed within a building to obtain sufficient VOC removal cannot be accurately determined base solely on a LA or aboveground volume basis.

\section{Literature Cited}

Hines, A.L., T.K. Ghosh, S.K. Loylka, and R.C. Warder, Jr. 1993. Indoor air: Quality and control. Prentice Hall, Englewood Cliffs, NJ.

Kays, S.J. 2011. Phytoremediation of indoor airCurrent state of the art, p. 3-21. In: Kim, J.K. (ed.). The value creation of plants for future urban agriculture. Nat. Inst. Hort. Herbal Science, RDA, Suwon, Korea.

Kim, K.J., M.J. Kil, J.S. Song, E.H. Yoo, K.C. Son, and S.J. Kays. 2008. Efficiency of volatile formaldehyde removal by indoor plants: Contribution of aerial plant parts versus the rootzone. J. Amer. Soc. Hort. Sci. 133:1-6.

Kim, K.J. and H.D. Lee. 2008. Development of model and calculating equation for the rate of volatile formaldehyde removal of indoor plants. Hort. Environ. Biotechnol. 49:1-7.

Kim, K.J., E.H. Yoo, M.I. Jeong, J.S. Song, S.Y Lee, and S.J. Kays. 2011. Changes phytoremediation potential of indoor plants with exposure to toluene. HortScience 46:16461649.

Wolverton, B.C. and J.D. Wolverton. 1993. Plants and soil microorganism: Removal of formaldehyde, xylene, and ammonia from the indoor environment. J. Mississippi Acad. Sci. 38:11-15.

Zhang, H., S.V. Pennisi, S.J. Kays, and M.Y. Habteselassie. 2013. Isolation and identification of toluene-metabolizing bacteria from rhizospheres of two indoor plants. Water Air Soil. Pollut. 224:1648. 